\title{
IMPLEMENTASI DAN ANALISIS DATA LOGGER SENSOR TEMPERATURE MENGGUNAKAN WEB SERVER BERBASIS EMBEDDED SYSTEM
}

\author{
Anak Agung Gde Ekayana') \\ 1 Sistem Komputer, STMIK STIKOM Indonesia \\ Email: ekayana888@gmail.com
}

\begin{abstract}
ABSTRAK
Saat melakukan suatu riset yang menggunakan komponen sensor (sensor suhu), kebanyakan para periset memilih sensor tanpa memahami spesifikasi yang dimiliki dari sensor tersebut. Berdasarkan obervasi dan pengumpulan data yang didapatkan, sensor yang digunakan menggunakan sensor yang pada saat itu banyak digunakan, tanpa memahami dan menganalisis kebutuhan sensor terhadap objek yang akan diukur. Maka untuk mengatasi kesenjangan tersebut pada penelitian ini bertujuan mengimplementasikan suatu web server sebagai data logger dari beberapa sensor temperature dan selanjutnya di lakukan analisis pada data-data yang didapatkan untuk mendapatkan hasil yang spesifik dari sensor tersebut. Penelitian ini menggunakan metode rancang bangun, rancang bangun yang digunakan meliputi rancang bangun perangkat hardware berupa embedded system dari sensor-sensor, mikrokontroler dan komunikasi data, sedangkan rancang bangun perangkat software berupa implementasi web server sebagai tempat data dari pengukuran sensor-sensor temperature. Hasil penelitian menunjukkan bahwa dari empat sensor temperature yang digunakan dan di bandingkan dengan hasil dari alat ukut standar, didapatkan pada sensitivitas sensor DHT 11 dan DS18B20 mendekati hasil dari alat ukur, sedangkan LM 35 dan Termistor sensitivitas cenderung lambat dan hasilnya banyak terjadi fluktuatif saat digunakan sebagai alat ukur. Tanggapan waktu diantara sensor tersebut dapat diurutkan dari yang tercepat, yaitu DS18B20, DHT 11, thermistor dan LM 35.
\end{abstract}

Kata kunci: sensor, temperature, analisis, embedded

\begin{abstract}
When doing research that uses sensor components (temperature sensors), most researchers choose sensors without understanding the specifications of the sensors. Based on the observation and data collection obtained, the sensor used is more imitating or using sensors that are currently widely used, without understanding and analyzing the sensor needs of the object to be measured. So to overcome this gap in this study aims to implement a web server as a data logger of several temperature sensors and then an analysis of the data obtained to obtain specific results from these sensors. This research uses the design method, the design used includes the design of hardware devices in the form of embedded systems of sensors, microcontrollers and data communications, while the design of software devices in the form of web server implementation as a place of data from temperature sensor measurements. The results showed that of the four temperature sensors used and compared with results from standard measurement devices, it was found that the sensitivity of the DHT 11 and DS18B20 sensors approached the results of the measuring instrument, whereas the LM 35 and Thermistor sensitivity tended to be slow and the results were fluctuating when used as measuring instrument. The response time between the sensors can be sorted from the fastest, namely DS18B20, DHT 11, thermistor and LM 35
\end{abstract}

Keywords : sensor, temperature, analisys, embedded 


\section{PENDAHULUAN}

Proses sistem kendali pada kegiatan perindustrian maupun kegiatan lainnya merupakan bagian dari sistem instrumentasi, sistem instrumentasi merupakan dasar dari setiap sistem pengukuran yang dilakukan, baik berupa sinyal analog maupun sinyal digital. Pengukuran suatu variable, antara lain: suhu, cahaya, kelembaban udara, merupakan suatu masalah penelitian yang sering ditemui pada karya tulis pada bidang sistem elektornika dan mikrokontroler. Salah satu aplikasi dari sistem intrumentasi adalah akuisisi data. Akusisi data merupakan proses monitoring dan kontrol dari suatu objek dengan menggunakan sensor yang relevan, sehingga diperoleh data-data yang valid dari objek yang diukur. Pengukuran fisis adalah salah satu langkah dalam akuisisi data[1]. Berdasarkan hasil observasi dan penyebaran kuesioner pada responden secara acaka, memberikan hasil dewasa ini setiap riset yang mengangkat tema mengenai pengukuran/monitoring suhu pastinya menggunakan sensor yang paling banyak digunakan atau yang telah digunakan sebelumnya, dengan anggapan bahwa hasilnya sama, walaupun jika digunakan pada tempat, objek, waktu yang berbeda. Hasil observasi dan kuesioner yang telah dilakukan kepada responden mahasiswa yang dipilih secara acak/random memberikan tanggapan yang cukup beragam, antara lain: karena penelitian sebelumnya menggunakan sensor tersebut, agar lebih mudah karena sudah ada yang mengerjakan sebelumnya, dan karena harganya murah, hasil observasi ini didukung oleh penelitian [2] Pada sistem pemantauan atau monitoring suhu untuk mengetahui kondisi temperatur suhu ruangan maka diperlukan sensor suhu yang digunakan menjadi salah satu komponen yang sifatnya krusial atau berpengaruh terhadap kemampuan pembacaan sensor dan hasil pengukuran yang presisi. Pemilihan penggunaan tipe, jenis dan spesifikasi sensor tersebut akan sangat berpengaruh terhadap kinerja dan data yang diukur oleh sistem monitoring yang diterapan untuk mengetahui besarnya temperatur yang ada pada ruangan. Pada riset yang dilakukan lebih mengarah pada kolaborasi antara sistem informasi dengan embedded system. Embedded System merupakan salah satu dari sekian banyak bidang ilmu yang sangat intens dalam penggunaan dan pengembangan teknologi, salah satu teknologi yang berperan penting untuk saat ini adalah automatic system. Automatic sytem merupakan suatu pengembangan teknologi yang mengarah pada efisiensi kegiatan manusia, contohnya monitoring dan kontrol suatu perangkat menggunakan komputer dan handphone. Suatu sistem Embedded yang digunakan sebagai pengolah data/sinyal dari sensor, sudah terdapat firut Analog Digital to Converter (ADC) yang dapat mengubah dari analog ke digital. Pengubah analog ke digital (atau analog-to digital converters selanjutnya disebut ADC ) memiliki peran penting dalam sistem digital karena terkait peranannya dalam mengubah sinyal masukan analog menjadi sinyal keluaran digital. ADC membentuk antarmuka yang penting untuk menganalisa data analog dengan sebuah komputer digital maupun mikrokontroler dan merupakan bagian yang sangat diperlukan dalam sistem komunikasi digital untuk mentransmisikan sinyal analog dari sisi pengirim untuk kemudian didigitalisasi di sisi penerima.

Analog Digital to Converter (ADC) yaitu mengolah dan menkonversi besaran analog menjadi sinyal digital dari sensor suhu yang digunakan. Sensor suhu yang digunakan yaitu sensor LM35, DS18b20, Termistor dan DHT11, data dari masing-masung sensor dibandingkan hasilnya dengan alat ukur suhu standar, mikrokontroler Arduino Uno dan ESP8266 digunakan untuk mengolah data dan mengirim data pada web server Thingspeak, sehingga hasil penelitian ini memberikan hasil bagi para peneliti selanjutnya yang mengambil tema pengukuran temperatur agar lebih cermat dalam penggunaan sensor, tentunya hal ini berdampak pada hasil pengukuran yang sesuai dengan keadaan yang sebenarnya. Agar penelitian yang dilakukan lebih valid dan terarah, beberapa penelitian yang relevan dapat dijadikan rujukan, antara lain: penelitian oleh Ari Rahayuningtyas, dkk (2016) yang dipublikasikan pada Jurnal Penelitian dan Pengabdian Masyarakat, pada penelitian ini menyimpulkan bahwa dalam pengontrolan suhu ruangan pengeringan menggunakan sensor LM35 dan mikrokontroler yang digunakan menggunakan ATmega 8535, dari pengujian yang dilakukan antara LM35 dengan alat ukur suhu yang standar masih terdapat selisih namun tidak terlalu besar. Terlihat bahwa pembacaan antara sensor suhu LM35 dan termometer raksa tidak berbeda jauh. Jika terdapat beda itu masih diijinkan karena masih dalam batas toleransi[3], penelitian oleh Desmon Kendek Allo, dkk (2103) yang dipublikasikan pada E-Journal Teknik Elektro dan Komputer, pada penelitian ini menyimpulkan bahwa penggunaan sensor LM35 untuk mengukur suhu air masih belum mampu memberikan hasil yang optimal, kenaikan tegangan sensor sebesar 0,01 volt dan tingkat error yang terjadi dalam penggunaan sensor LM 35 berkisar antara 0,73 - 1,93\%[4], penelitian oleh Lenty Marwani, dkk (2017) yang dipublikasikan pada Jurnal Mutiara Elektromedik, pada penelitian ini menggunkan senor DHT11 sebagai sensor untuk mengukur temperatur dari inkubator bayi, mikroprosesor yang digunakan adalah ATmega 8535. Penggunaan sensor DHT11 masih terdapat error sebesar $1,02 \%$ yang dibandingkan dengan alat ukur thermometer[5]. 


\section{A. Sensor Temperatur}

Sensor Temperatur atau sensor suhu adalah suatu komponen yang dapat mengubah besaran panas dari suatu tempat menjadi besaran listrik, sehingga dapat mendeteksi gejala perubahan suhu pada obyek tertentu. Sensor suhu melakukan pengukuran terhadap jumlah energi panas/dingin yang dihasilkan oleh suatu obyek sehingga memungkinkan kita untuk mengetahui gejala perubahanperubahan suhu tersebut dalam bentuk output Analog maupun Digital. Berikut ini adalah jenis-jenis sensor yang akan digunakan pada penelitian ini,antara lain:

1) Sensor LM 35

Sensor suhu LM 35 merupakan suatu komponen elektronika yang digunakan untuk mentransformasikan besaran suhu menjadi besaran listrik dalam bentuk tegangan. Pada dasarnya LM35 memiliki keluaran impedansi yang rendah dan linieritas yang tinggi sehingga sensor ini dapat dihubungkan dengan rangkaian kendali[6]. LM35 berupa rangkaian terintegrasi (IC) dengan tegangan keluaran yang berbanding lurus terhadap suhu dalam derajat Celcius. LM35 beroperasi pada suhu dengan rentang $55^{\circ} \mathrm{C}-150^{\circ} \mathrm{C}$. Sensor ini memiliki skala liner $10 \mathrm{mV} /{ }^{\circ} \mathrm{C}$, yang berarti bahwa setiap kenaikan suhu $1^{\circ} \mathrm{C}$ akan menaikkan tegangan keluaran dari sensor LM35, bentuk dan formula dari sensor LM 35 dapat tampilkan sebagai berikut:

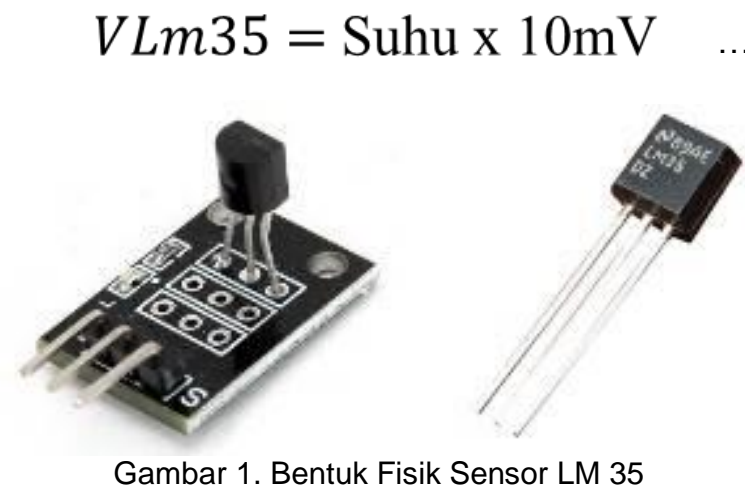

2) Sensor DHT 11

Sensor suhu DHT 11 merupakan keluarga dari sensor temperatur, selain suhu, sensor ini mampu mengukur kelembaban udara disekitarnya. Keluaran sensor DHT11 berupa sinyal digital yang sudah terkalibrasi. Jangkauan pengukuran temperatur dari sensor ini adalah $0-50^{\circ} \mathrm{C}[7]$ dan jangkaian pengukuran kelembaban relative sebesar $20-90 \%$. Sensor DHT11 membutuhkan catu daya sebesar $3-5,5$ volt DC. Keakuratan untuk temperatur sebesar $\pm 2 \%[8]$. Sensor DHT 11 memiliki resolusi $1^{\circ} \mathrm{C}[9]$. Bentuk fisik dari sensor DHT 11 ditunjukan pada Gambar 2.
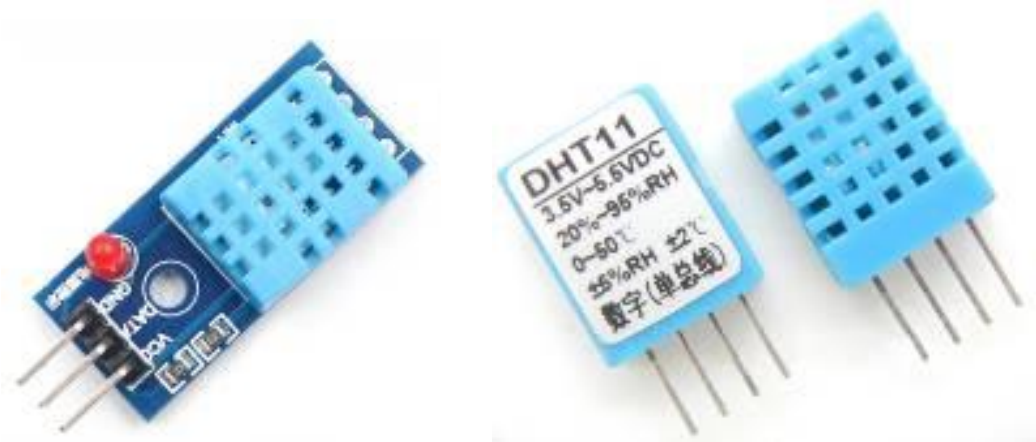

Gambar 2. Bentuk Fisik Sensor DHT 11

3) Sensor Ds18b20

Sensor suhu DS18B20 adalah sensor suhu yang memiliki keluaran digital. DS18B20 memiliki tingkat akurasi yang cukup tinggi, yaitu $0,5^{\circ} \mathrm{C}$ pada rentang suhu $-10^{\circ} \mathrm{C}$ sampai $+85^{\circ} \mathrm{C}$. Sensor suhu pada umumnya membutuhkan ADC dan beberapa pin port pada mikrokontroler, namun DS18B20 ini tidak membutuhkan ADC agar dapat berkomunikasi dengan mikrokontroler dan hanya membutuhkan 
1 wire saja[10]. Sensor suhu DS18b20 memiliki sensitivitasnya tidak terlalu tinggi dan bersifat digital sehingga tegangan yang dihasilkan oleh sensor suhu DS18B20 tidak perlu dikonversi. Berikut bentuk fisik dari sensor Ds18b20.
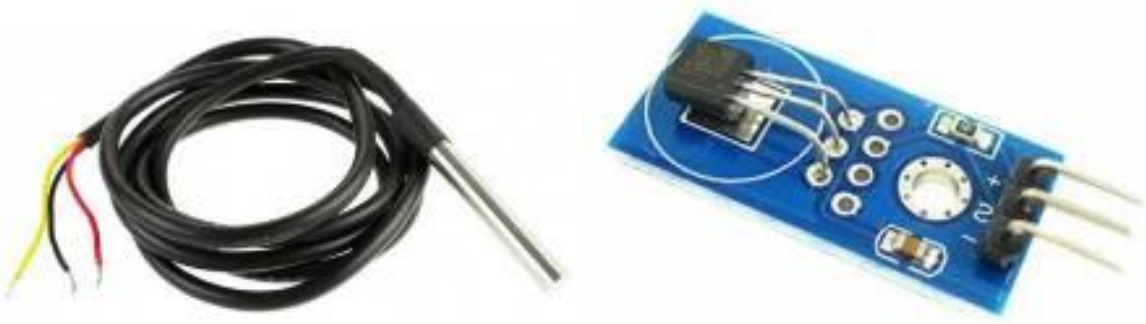

Gambar 3. Bentuk Fisik Sensor Ds18b20

4) Sensor Thermistor

Thermistor merupakan salah satu keluarga resistor yang peka terhadap perubahan temperatur, pada umumnya ada dua tipe dasar thermistor yaitu NTC (Negative Temperature Coeffficient) dan PTC (Positive Temperature Coefficient). Tipe thermistor NTC paling cocok digunakan pada pengukuran temperatur yang presisi, sedangkan untuk tipe PTC paling cocok digunakan sebagai aplikasi saklar elektronik yang peka terhadap perubahan temperatur[11]. Berikut ini bentuk fisik dari sensor thermistor
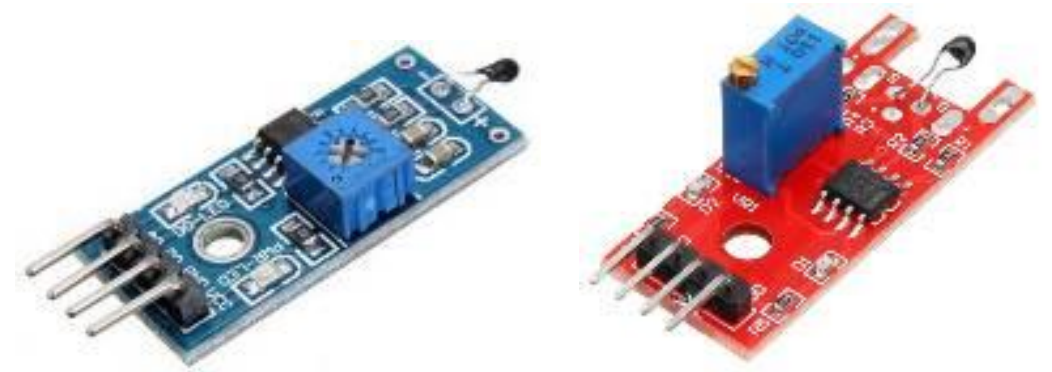

Gambar 4. Bentuk fisik sensor Thermistor

5) Sensor Thermokopel

Termokopel merupakan sensor suhu yang mengubah perbedaan suhu menjadi perubahan tegangan, hal ini disebabkan oleh perbedaan kerapatan yang dimiliki oleh masing-masing logam yang bergantung pada massa jenis logam, sensor termokopel selain dapat membaca perubahan suhu juga dapat berperan sebagai input analog pada sebuah sistem kendali[12]. Bentuk fisik dari sensor termokopel diperlihatkan pada Gambar 5.
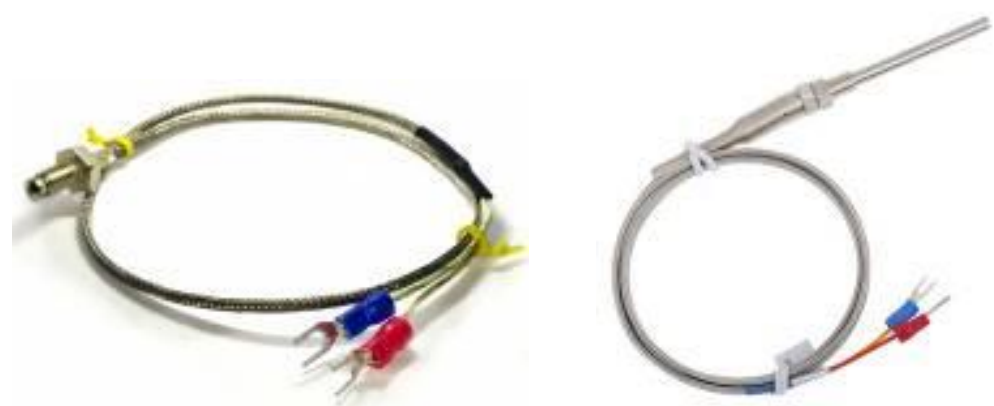

Gambar 5. Bentuk fisik sensor Thermokopel

\section{B. Thingspeak}

Thingspeak merupakan sebuah layanan yang menawarkan platform analisis yang memungkinkan para periset untuk mengumpulkan, memvisualisasi dan menganalisis aliran data secara langsung di cloud. Thingspeak memberikan fitur memvisualisasi secara langsung data yang telah dikirimkan dari perangkat mikrokontroler ke thingspeak. Thingspeak dalam menunjang hasil yang lebih spesifik bisa dikolaborasikan dengan aplikasi MATLAB. 
Thingspeak awalnya diluncurkan oleh ioBridge pada tahun 2010 sebagai layanan untuk mendukung aplikasi IOT.

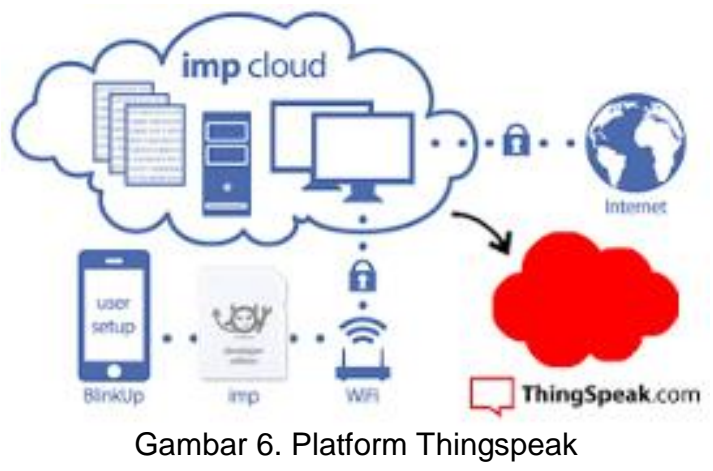

\section{METODE}

Penelitian ini dilakukan berdasarkan metode rancang bangun dengan tahapan studi literatur, perumusan masalah, perancangan, pembuatan sistem, dan pengujian sistem, serta kesimpulan seperti ditunjukan pada Gambar 7 berikut.

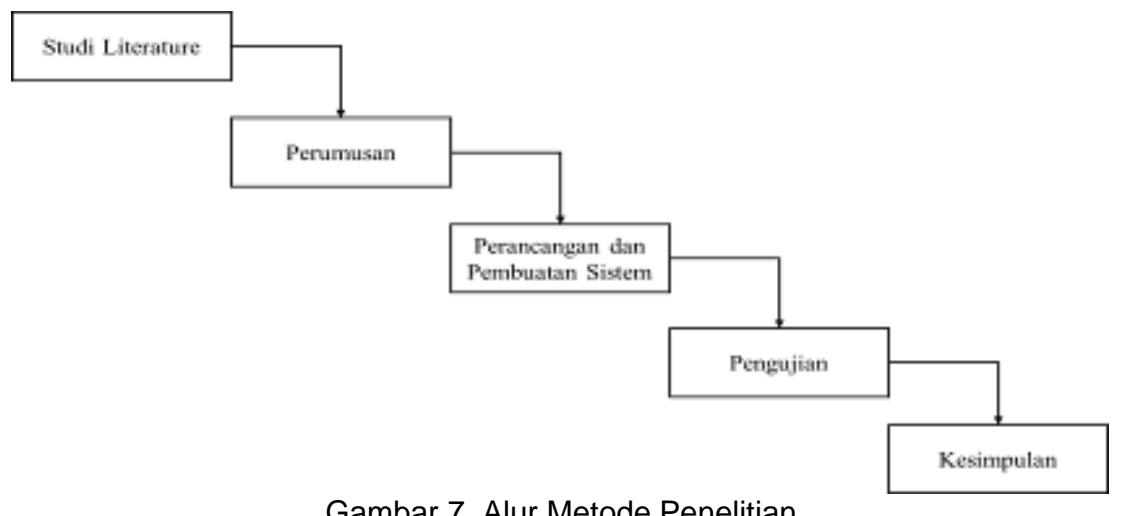

Studi literatur dan perumusan dilakukan sebelum penelitian, dalam tahapan pertama dan kedua, penulis sudah melakukan beberapa kegiatan antara lain: mereview beberapa jurnal yang relevan dengan topik penelitian, melakukan obervasi kepada mahasiswa yang mengambil tugas akhir. Faktafakta yang didapatkan selanjutnya diolah untuk menjadi data dalam penelitian ini.

1) Perancangan Perangkat Keras Sistem

Sistem tersusun dari beberapa blok, diantaranya adalah blok Embedded System, modul wifi esp8266, 5 tipe sensor suhu. Gambar blok diagram sistem ditunjukkan pada

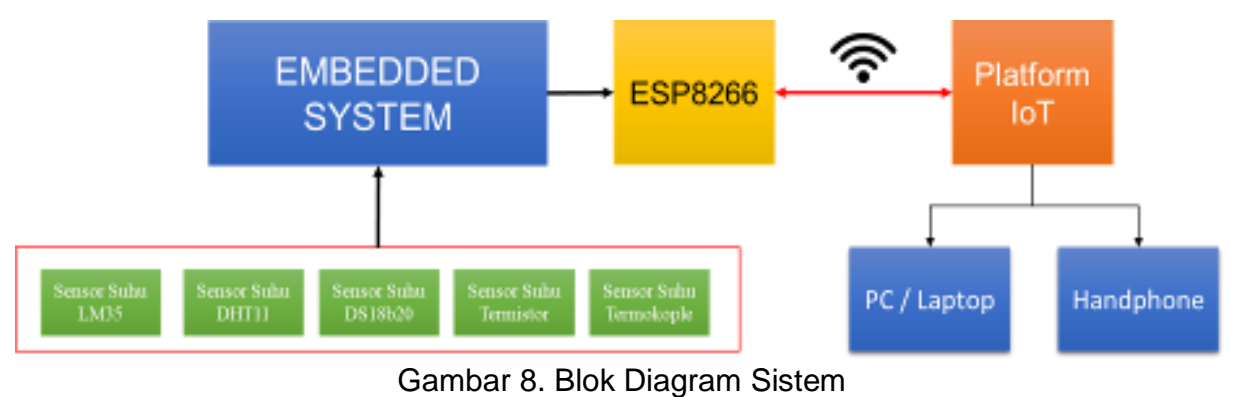

Perancangan rangkaian skematik untuk sistem embedded direncanakan seperti pada Gambar 9, pada perancangan skematik menggunakan lima sensor yang di hubungkan ke mikrokontroler secara parallel, port yang digunakan sebanyak 3 port untuk analog dan 2 port untuk digital. ESP8266 disambungkan dengan RX dan TX mikrokontroler untuk komunikasi data. 


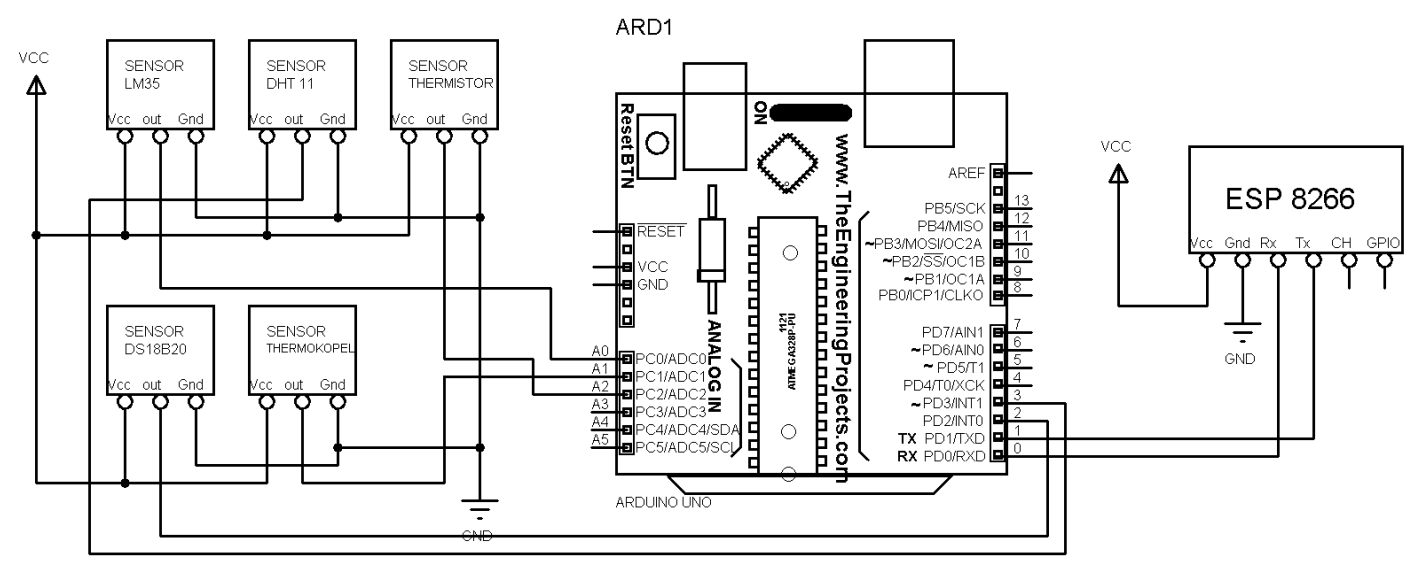

2) Perancangan Web Server

Gambar 9. Skematik Rangkaian

Web server yang dirancang menggunakan platform Internet of Things pada Thingspeak, sesuai dengan fungsinya thingspeak merupakan salah satu platform Internet of Things yang dapat diakses tanpa berbayar, penggunaan platform ini sekaligus menjadi contoh untuk bisa dikembangkan pada tugas akhir mahasiswa
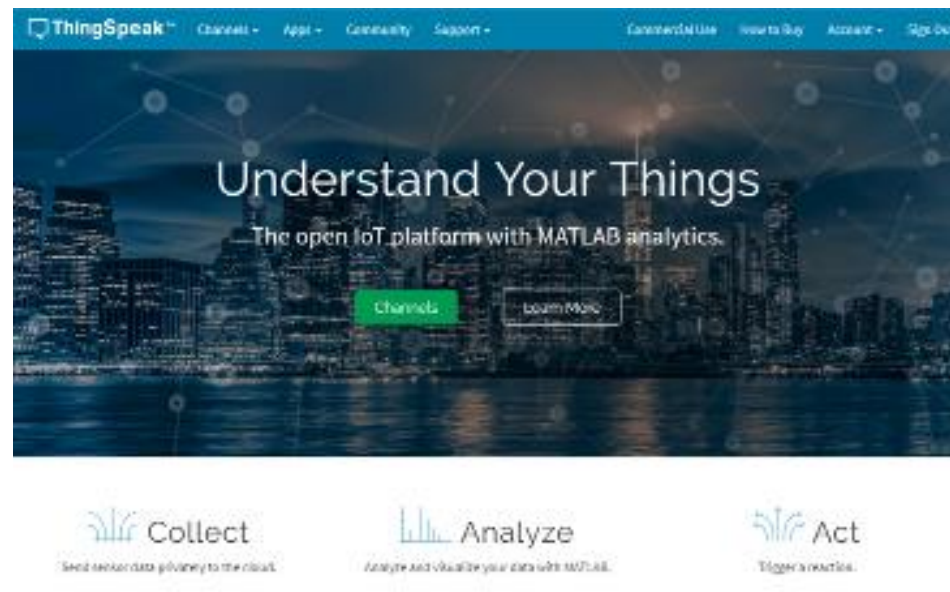

Gambar 10. IoT Thingspeak

\section{HASIL DAN PEMBAHASAN}

\section{A. Hasil Penelitian}

Setiap data yang dikirim oleh sistem (perangkat keras) disimpan pada field yang ada di channel thingspeak, selanjutnya data tersebut bisa diexport guna dilakukan analisis lanjutan. Hasil penelitian ini didukung oleh beberapa penelitian dari [13], Pada jurnal ini ditampilkan sebagian dari hasil keseluruhan data yang ada, harapannya sample data tersebut dapat digunakan untuk merepresentasikan data-data yang lainnya. Skenario pengujian dilakukan pada suatu ruang yang suhunya sudah di tentukan terlebih dahulu, setelah itu suhu dirubah secara simultan dan hasilnya pembacaan sensor di rekam pada web server. Hasil-hasil perekaman data sensor selanjutnya dibandingkan dengan hasil pembacaan dari Thermometer. Hasil pembacaan data sensor yang direkam oleh sistem dapat dilihat pada Tabel1 berikut ini.

Tabel 1. Hasil Kinerja Sensor dan Themometer pada suhu ruang $25^{\circ} \mathrm{C}$

\begin{tabular}{ccccccc}
\hline \multirow{2}{*}{ Pengujian } & THERMOMETER & \multicolumn{5}{c}{ Sensor Temperatur } \\
\cline { 3 - 7 } & $\left({ }^{\circ} \mathrm{C}\right)$ & LM35 & DHT11 & DS18B20 & Thermistor & Termokopel \\
\hline 1 & 25 & 24 & 25 & 24 & 24 & 24 \\
\hline 2 & 25 & 24 & 25 & 24 & 25 & 24
\end{tabular}




\begin{tabular}{ccccccc}
3 & 25 & 24 & 25 & 25 & 25 & 24 \\
\hline 4 & 25 & 24 & 25 & 25 & 24 & 24 \\
\hline 5 & 25 & 24 & 25 & 25 & 23 & 24 \\
\hline 6 & 25 & 24 & 25 & 25 & 24 & 24 \\
\hline 7 & 25 & 24 & 24 & 25 & 24 & 24 \\
\hline 8 & 25 & 24 & 25 & 25 & 24 & 24 \\
\hline 9 & 25 & 24 & 25 & 25 & 24 & 24 \\
\hline 10 & 25 & 24 & 25 & 25 & 24 & 24 \\
\hline
\end{tabular}

Pada Tabel 1 dapat dilihat pengambilan data pada masing-masing sensor dengan banyak data yang diambil berjumlah 10 kali pengujian, hasil pembacaan sensor dibandingkan dengan hasil dari alat ukur thermometer. Perbandingan ini dilakukan untuk menganalisis tingkat presisi suatu sensor dengan thermometer, jika hasil sensor mendekati atau sama dengan hasil termometer bisa dipastikan sensor dapat digunakan sebagai pengganti termometer dikemudian hari.

Tabel 2. Hasil Kinerja Sensor dan Themometer pada suhu ruang $28^{\circ} \mathrm{C}$

\begin{tabular}{ccccccc}
\hline \multirow{2}{*}{ Pengujian } & THERMOMETER & \multicolumn{5}{c}{ Sensor } \\
\cline { 3 - 7 } & $(\mathrm{OC})$ & LM35 & DHT11 & DS18B20 & Thermistor & Termokopel \\
\hline 1 & 28 & 27 & 28 & 28 & 28 & 28 \\
\hline 2 & 28 & 27 & 28 & 28 & 28 & 28 \\
\hline 3 & 28 & 28 & 28 & 28 & 27 & 28 \\
\hline 4 & 28 & 28 & 28 & 28 & 27 & 28 \\
\hline 5 & 28 & 28 & 28 & 28 & 27 & 27 \\
\hline 6 & 28 & 28 & 28 & 28 & 27 & 27 \\
\hline 7 & 28 & 27 & 28 & 28 & 27 & 27 \\
\hline 8 & 28 & 28 & 28 & 28 & 27 & 27 \\
\hline 9 & 28 & 28 & 27 & 29 & 28 & 27 \\
\hline 10 & 28 & 28 & 28 & 29 & 28 & 27 \\
\hline
\end{tabular}

Tabel 3. Hasil Kinerja Sensor dan Themometer pada suhu ruang $30^{\circ} \mathrm{C}$

\begin{tabular}{ccccccc}
\hline \multirow{2}{*}{ Pengujian } & $\begin{array}{c}\text { THERMOMETER } \\
(\mathrm{OC})\end{array}$ & \multicolumn{6}{c}{ Sensor } \\
\cline { 3 - 7 } & 30 & 30 & 29 & 30 & 29 & 30 \\
\hline 1 & 30 & 30 & 30 & 29 & 29 & 29 \\
\hline 2 & 30 & 30 & 30 & 30 & 30 & 30 \\
\hline 3 & 30 & 29 & 30 & 30 & 30 & 30 \\
\hline 4 & 30 & 29 & 30 & 30 & 30 & 30 \\
\hline 5 & 30 & 30 & 30 & 30 & 30 & 30 \\
\hline 6 & 30 & 30 & 30 & 30 & 30 & 30 \\
\hline 7 & 30 & 30 & 30 & 30 & 30 & 30 \\
\hline 8 & 30 & 30 & 30 & 30 & 30 & 30 \\
\hline 9 & 30 & 30 & 30 & 30 & 30 & 29 \\
\hline 10 & 30 & & & & & \\
\hline
\end{tabular}

Hasil pengujian dari keseluruhan perangkat yang dirancang, dilakukan uji coba sebanyak 3 keadaan yaitu pada suhu $25^{\circ} \mathrm{C}, 28^{\circ} \mathrm{C}$ dan $30^{\circ} \mathrm{C}$, tiga keadaan itu dipilih sebagai perbandingan hasil suhu dari sensor dengan alat ukur termometer, tiga keadaan itu dirasa cukup untuk menganalisis kinerja dari sensor temperatur, ruangan yang digunakan pada proses pengujian menggunakan suatu ruang yang telah di atur suhunya, sehingga data yang direkam lebih valid pada suhu yang sudah 
diatur. Pada tabel diatas dapat dilihat hasil dari perekaman data dari sensor dan thermometer, data sensor diambil sebanyak 10x pengujian dengan rentang waktu yang berbeda-beda. Hasil kinerja yang telah didapatkan selanjutnya dikonversi kedalam grafik garis untuk lebih memvisualisasi kinerja dari masing-masing sensor.

Adapun temuan yang dapat dianalisis dari hasil perbandingan sensor dengan alat ukur thermometer bahwa sensor DHT11 memberikan pengukuran yang lebih presisi daripada sensor suhu lainya, terlihat hasil pengukuran sensor DHT11 sama dengan alat ukur Thermometer, sensor DS18B20 dan LM 35 telihat sering terjadi flusktuatif hasil pengukuran, tetapi masih dibatas ditoleransi untuk hasil pengukurannya. Sensor termistor dan termokopel memiliki hasil pengukuran yang masih banyak terdapat penyimpangan dari perbandingan dengan thermometer, hasil pengukuran sensor termistor lebih baik daripada termokopel, perbedaan hasil pengukuran ini memberikan gambaran bahwa tidak semua sensor suhu bisa digunakan dalam sistem intrumentasi, terlebih lagi dalam bidang akuisisi data. Grafik kinerja dari masing-masing sensor dan termometer dapat dilihat berikut pada gambar 11 berikut ini.

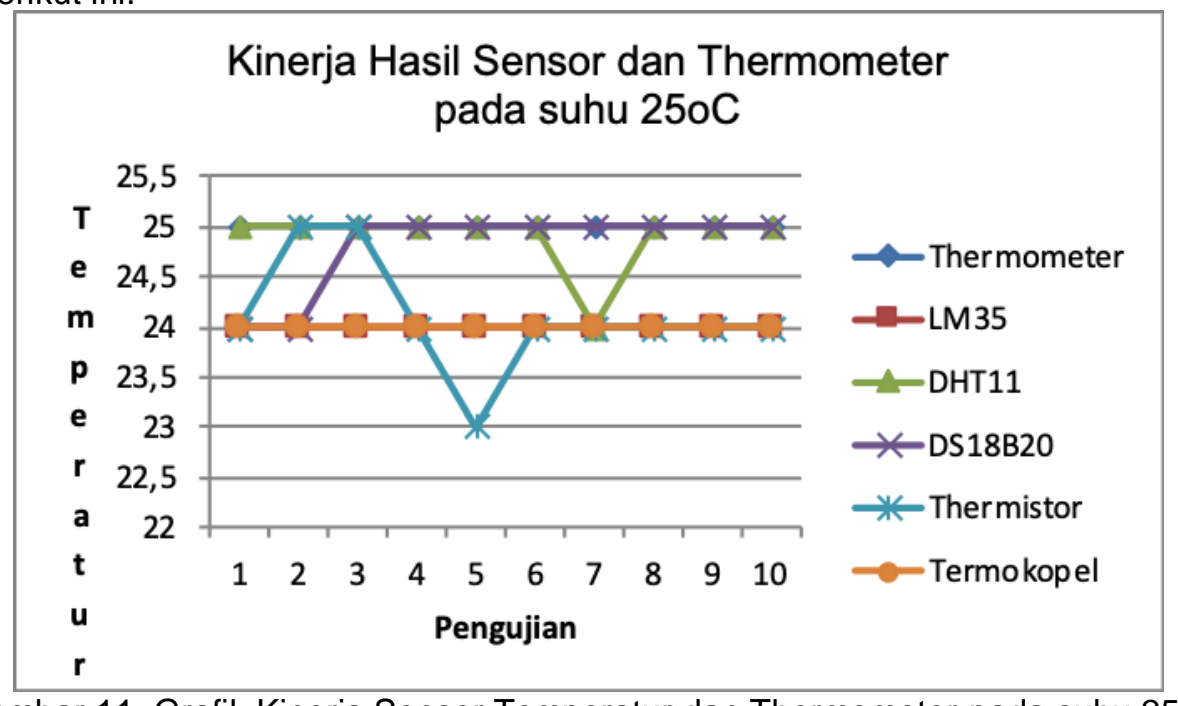

Gambar 11. Grafik Kinerja Sensor Temperatur dan Thermometer pada suhu $25^{\circ} \mathrm{C}$

Pada grafik diatas dapat dijelaskan bahwa implementasi dari embedded system berjalan dengan baik, hasil dari masing-masing sensor juga bisa direkam secara realtime. Pada saat pengujian sensor pada suatu ruang dengan suhu yang telah diatur yaitu $25^{\circ} \mathrm{C}$, didapatkan hasil pengukuran dari sensor DHT 11 lebih presisi daripada 4 sensor lainya. Perbedaan yang terjadi pada sensor DHT 11 terbilang masih wajar daripada sensor lainnya, sensor LM 35 menempati ukuran kedua yang hasil pengukurannya mendekati presisi dari hasil thermometer, pada sensor LM 35 untuk mendapatkan hasil yang stabil dan presisi perlu ditambahkan rangkaian pengkondisian sinyal, karena hasil keluaran dari sensor LM 35 masih terbilang kecil dan terlalu dinamis sepanjang proses pengukuran, hasil pengujian didukung oleh hasil penelitian yang relevan [14].

Dua sensor selanjutnya yaitu thermistor dan termokopel memberikan hasil pengukuran yang kurang presisi dari thermometer, tetapi masih dibatas toleransi dari hasil pengukuran suhu, jika di analisi lebih jauh, sensor thermistor dan termokopel lebih relevan dalam pengukuran suhu benda/objek yang dipanaskan, dan karakteristik sensor ini ditempel pada benda yang akan diukur, contohnya pada dispenser dan rice cooker. 


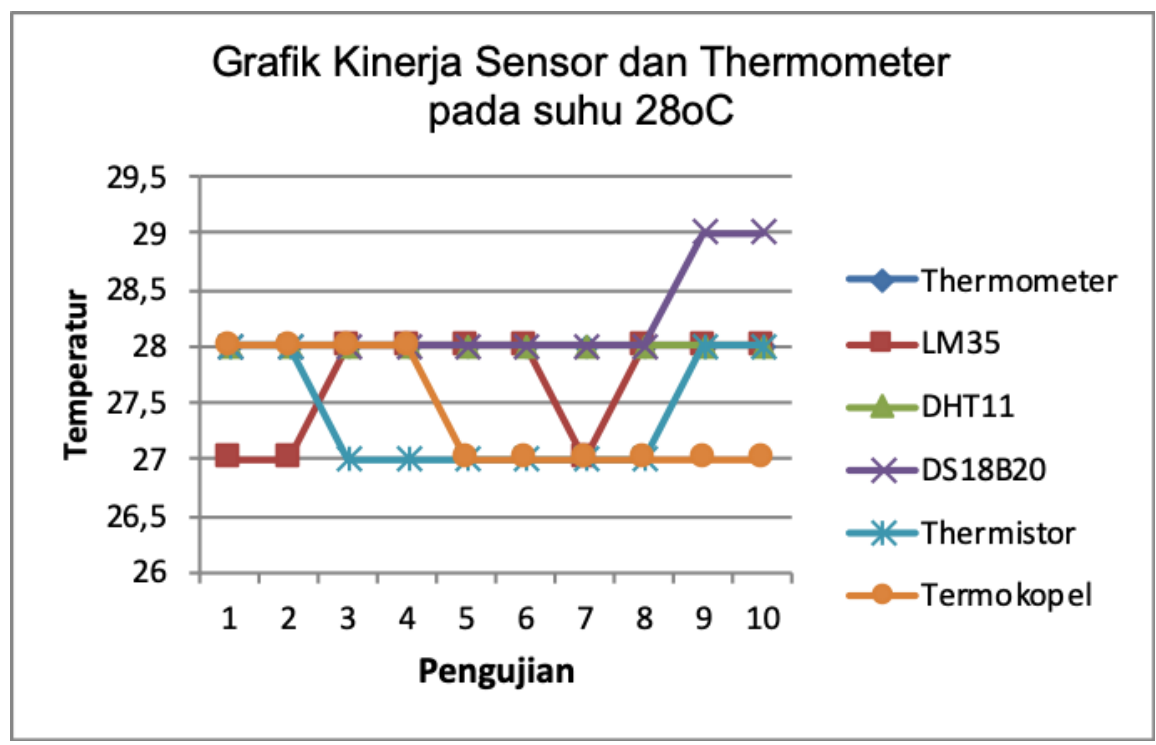

Gambar 12. Grafik Kinerja Sensor Temperatur dan Thermometer pada suhu $28^{\circ} \mathrm{C}$

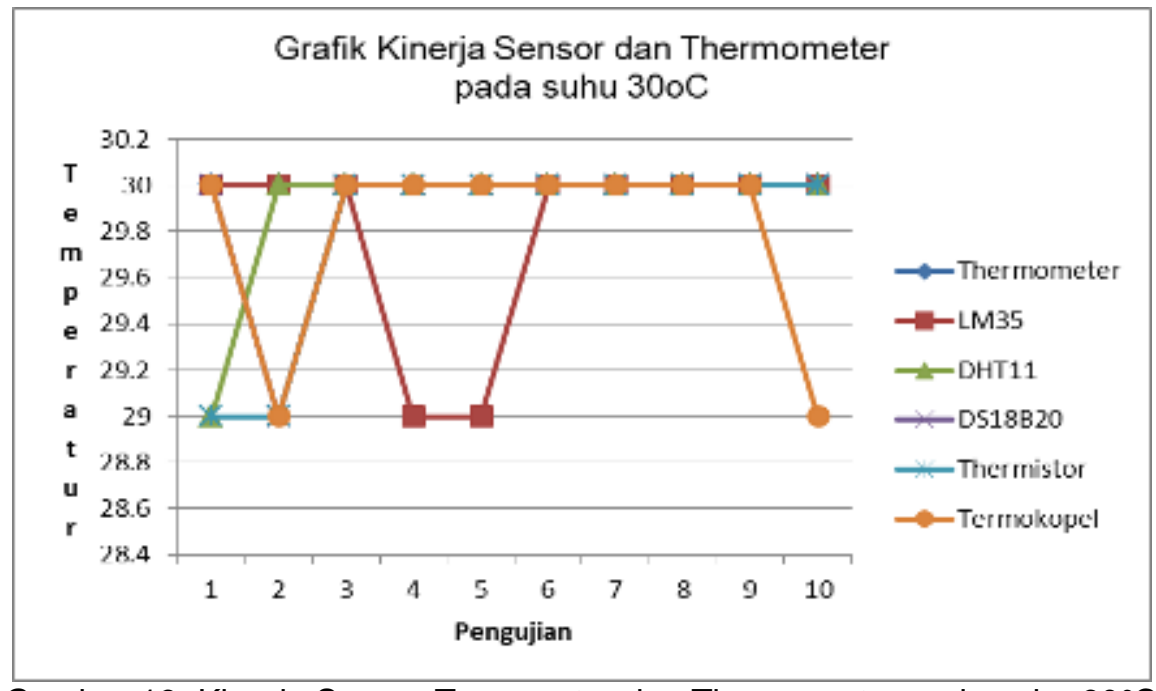

Gambar 13. Kinerja Sensor Temperatur dan Thermometer pada suhu $30^{\circ} \mathrm{C}$

Berdasarkan tahapan implementasi, uji coba dan analisis yang telah dilakukan pada penelitian ini, dapat di telaah lebih lanjut bahwa pengukuran suatu objek sangat memerlukan sensor yang memiliki spesifikasi dari objek tersebut. Selain uji coba pada suatu ruangan menggunakan kelima sensor tersebut, pada penelitian ini juga melakukan uji coba di luar ruangan/outdoor, objek logam yang dipanaskan dan diukur suhunya, dan di dalam air. Hasil yang diperoleh dari uji coba secara random tersebut, sensor termokopel dan termistor sangat relevan digunakan pada objek yang menghasilkan panas, seperti, tangki, mesin kendaraan, plat besi/baja, karakteristik dari sensor tersebut juga dinilai sangat baik, sebab fisik dari sensor tersebut mampu bertahan dan tidak mudah meleleh pada objek yang diukur. Hasil uji coba yang kedua, dapat di analisis, pada sensor DS18B20 memiliki kemampuan untuk mengukur temperatur di dalam air, sebab sensor ini mempunyai elektroda yang kedap air, sehingga jika sensor ini dimasukkan kedalam air masih mampu untuk melakukan proses pengukuran dan hasil yang dihasilkan juga tidak terlalu berbeda dengan alat ukur termometer, sedangkan sensor LM 35 dan DHT 11 dilihat dari bentuk fisiknya sangat relevan untuk mengukur suhu di dalam dan di luar ruangan, dari pengujian sensor LM 35 dan DHT 11 di luar ruangan memberikan hasil pengukuran yang cukup baik, jika sensor ini digunakan di luar ruangan, sangat perlu diperhatikan untuk tidak terkena sinar matahari secara langsung, jika terjadi maka pembacaa suhu akan mengalami gangguan, sehingga hasilnya banyak yang tidak valid.

Hasil pengujian dan range suhu dari masing-masing sensor yang telah diuji coba, dapat dilihat seksama pada tabel berikut ini. 
Tabel 4. Pengujian dan range suhu masing-masing sensor

\begin{tabular}{|c|c|c|c|c|c|c|c|}
\hline \multirow[b]{2}{*}{ Sensor } & \multicolumn{6}{|c|}{ Tempat } & \multirow[b]{2}{*}{ Range Suhu } \\
\hline & Ruangan & Kamar & $\begin{array}{c}\text { Luar } \\
\text { Ruangan }\end{array}$ & Laboratorium & $\begin{array}{l}\text { Dalam } \\
\text { Air }\end{array}$ & $\begin{array}{c}\text { Panas suatu } \\
\text { benda }\end{array}$ & \\
\hline LM35 & V & V & V & V & $x$ & $x$ & $-50-150$ \\
\hline DHT11 & V & V & V & V & $x$ & $x$ & $0-50$ \\
\hline DS18B20 & V & V & V & V & V & $\mathrm{X}$ & $-55-125$ \\
\hline Thermistor & $\mathrm{V}$ & $\mathrm{V}$ & $\mathrm{V}$ & $\mathrm{V}$ & $\mathrm{x}$ & $\mathrm{V}$ & -40 to +165 \\
\hline Termokopel & V & V & V & V & $\mathrm{X}$ & V & -200 to 1250 \\
\hline
\end{tabular}

\section{SIMPULAN DAN SARAN}

Penelitian yang dilaksanakan memberikan hasil bahwa tidak semua sensor temperatur bisa digunakan untuk alat ukur yang optimal, dari beberapa jenis sensor yang digunakan sebagai riset, menunjukkan bahwa sensor DHT 11 dan sensor DS18B20 memiliki pembacaan suhu yang lebih baik, dari pada sensor LM 35 dan Thermistor. Data-data pembacaan sensor suhu menghasilkan bahwa alat ukur suhu yang optimal dapat menggunakan sensor DHT 11 dan DS18B20 sebagai alat ukur suhu di dalam maupun di luar runagan, untuk sensor DS18B20 bisa digunakan untuk pengukruan suhu ruangan dan di dalam air, sedangkan sensor thermistor dan termokopel relevan digunakan untuk mengukur suhu pada objek/benda yang dipanaskan atau menghasilkan panas, dari proses ujicoba yang dilakukan pada penelitian ini, setiap sensor suhu yang mampu memberikan hasil maximal dalam pengukuran suhu, jika di gunakan pada objek atau tempat yang tepat

Web Server loT dibangun menggunakan platform Internet of Thing dari Thingspeak, pada platform loT Thingspeak menggunakan field berjumlah 5 channel, karena dalam sistem ini menggunakan 5 buah sensor yang bekerja secara parallel untuk membaca variabel suhu. Data-data sensor yang dikirimkan melalui modul ESP8266 disimpan pada channel Thingspeak, nantinya data tersebut dirubah menjadi grafik garis agar lebih mudah dalam memonitoring perubahan suhu.

Hasil penelitian ini dapat dijadikan bahan rujukan atau bahan pertimbangan untuk para periset selanjutnya, dari penelitian ini maka disarankan referensi dalam pemilihan sensor suhu yang digunakan dalam penelitian atau riset yang akan dilakukan, sehingga hasil yang didapatkan pada pengukuran suhu lebih baik dan optimal. Pengembangan selanjutnya dapat diarahkan dalam pengembangan aplikasi loT yang lebih update pada bidang sistem monitoring.

\section{UCAPAN TERIMAKASIH}

Ucapan terimakasih ditujukan kepada Lembaga Penelitian dan Pengabdian Masyarakat yang telah memberikan kesempatan untuk melakukan penelitian PPDS dengan nomor kontrak 32/09/LPPM/PPDS/VII/2019 dan institusi STMIK STIKOM Indonesia sebagai penyandang dana penelitian ini

\section{DAFTAR PUSTAKA}

[1] M. Surur, S. Pramono, and E. Wahyudi, "Analisis Dua Sensor Suhu Berbasis Embeded Web Server," Semin. Nas. Univ. PGRI Yogyakarta, 2015.

[2] imul Royan, R. Primananda, and W. Kurniawan, "Analisis Performa Sistem Pemantauan Suhu Dan Kelembaban Berbasis Wireless Sensor Network," J. Pengemb. Teknol. Inf. dan IImu Komput., vol. 1, no. 12, pp. 1865-1874, 2017.

[3] Rahayuningtyas, A. Ari, I. Fajar, seri I. Kuala, and T. , Santoso, "Pemanfaatan LM35 Sebagai Sensor Suhu Otomatis Pada Sistem Pengontrolan Suhu Ruangan Pengering," Penelit. Dan Pengabdi. Masy., vol. 4, no. 1, pp. 7-12, 2016.

[4] D. K. Allo, M. E. Dringhuzen J. Mamahit. S.T., M. K. Drs. Bahrun, and M. Novi M. Tulung, ST, 
"Rancang Bangun Alat Ukur Temperatur Untuk Mengukur Selisih Dua Keadaan," E-Journal Tek. Elektro dan Komput., p. 3, 2013.

[5] L. Marwani, N. Demus, R. Firman, J. T. Elektromedik, F. Sain, and T. Dan, "Penggunaan sensor dht11 sebagai indikator suhu dan kelembaban pada baby incubator," J. Mutiara Elektromedik, vol. 1, no. 1, 2017.

[6] Yunidar, Alfisyahrin, and Y. Rahmad, "Analisa Kinerja Sensor Suhu NTC dan LM35 Dalam Sistem Pendeteksian Suhu Ruangan Berbasis Mikrokontroler AVR ATmega 16," J. Amplif., pp. 38-42, 2013.

[7] A. A. G. Ekayana, "Rancang Bangun Alat Pengering Rumput Laut Berbasis Mikorokontroler Arduino Uno," J. Pendidik. Teknol. dan Kejuru., vol. 13, no. 1, pp. 1-12, 2016.

[8] A. Najmurrokhman, A, Kusnandar, "Prototipe Pengendali Suhu Dan Kelembaban Untuk Cold Storage Menggunakan Mikrokontroler Atmega328 Dan Sensor Dht11," J. Teknol. Univ. Muhammadiyah Jakarta, vol. 10, no. 1, pp. 73-82, 2018.

[9] V. Firmansyah, "Aplikasi kalman filter pada pembacaan sensor suhu untuk pemantauan kondisi ruangan laboratorium vera firmansyah†," J. Mater. dan Energi Indones., vol. 08, no. 01, pp. 17, 2018.

[10] E. Nurazizah, M. Ramdhani, and A. Rizal, "Rancang Bangun Termometer Digital Berbasis Sensor DS18B20 Untuk Penyandang Tunanetra," Proceeding Eng., vol. 4, no. 3, pp. 32943301, 2017.

[11] M. Y. Mustar and R. O. Wiyagi, "Implementasi Sistem Monitoring Deteksi Hujan dan Suhu Berbasis Sensor Secara Real Time," J. IIm. Semesta Tek., vol. 20, no. 1, pp. 20-28, 2017.

[12] D. P. Sari, S. Rasyad, Amperawan, and S. Muslimin, "Kendali Suhu Air Dengan Sensor Termokopel Tipe-K Pada Simulator Sistem Pengisian Botol Otomatis," J. Ampere, vol. 3, no. 1, pp. 128-134, 2018.

[13] N. Lysbetti Marpaung and D. E. Ervianto, "Data Logger Sensor Suhu Berbasis Mikrokontroler ATmega 8535 dengan PC sebagai Tampilan," J. Ilm. Elit. Elektro, vol. 3, no. 1, pp. 37-42, 2012.

[14] D. Nopilawati and G. A. Pauzi, "Realiasasi Sensor Temperatur LM35DZ Sebagai Sensor Kecepatan Aliran Fluida Berbasis Mikrokontroler ATMega32 dengan Media Penyimpan Data Micro Secure Digital ( Micro SD )," J. Teor. dan Apl. Fis., vol. 04, no. 02, pp. 161-166, 2016. 